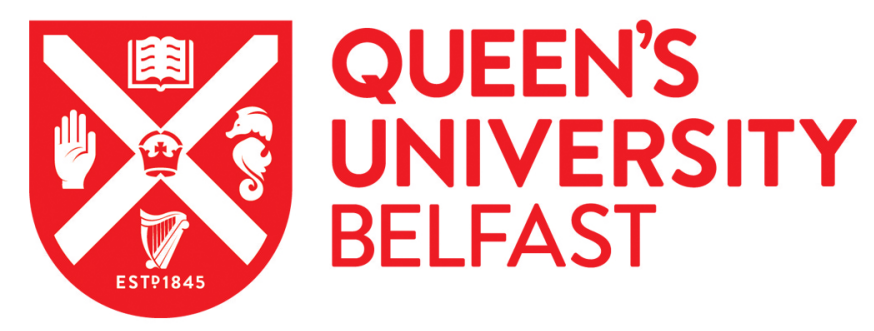

\title{
The effects of information and communication technologies on residential mobility and migration
}

Cooke, T. J., \& Shuttleworth, I. (2018). The effects of information and communication technologies on residential mobility and migration. Population, Space and Place, 24(3), 1-11. [e2111]. https://doi.org/10.1002/psp.2111

\section{Published in:}

Population, Space and Place

\section{Document Version:}

Peer reviewed version

Queen's University Belfast - Research Portal:

Link to publication record in Queen's University Belfast Research Portal

Publisher rights

Copyright 2018 Wiley. This work is made available online in accordance with the publisher's policies. Please refer to any applicable terms of use of the publisher.

\section{General rights}

Copyright for the publications made accessible via the Queen's University Belfast Research Portal is retained by the author(s) and / or other copyright owners and it is a condition of accessing these publications that users recognise and abide by the legal requirements associated with these rights.

Take down policy

The Research Portal is Queen's institutional repository that provides access to Queen's research output. Every effort has been made to ensure that content in the Research Portal does not infringe any person's rights, or applicable UK laws. If you discover content in the Research Portal that you believe breaches copyright or violates any law, please contact openaccess@qub.ac.uk. 


\section{Introduction ${ }^{1}$}

The widespread adoption of advanced information and communication technologies (ICTs) over the last 30 years has profoundly impacted geographic landscapes and their underlying geographic processes. For example, ICTs have intensified daily mobility behavior and altered daily mobility patterns by loosening ties to physical places, expanding daily activity spaces, and causing activities to fragment and blur across space and time (Schwanen, Dijst, \& Kwan, 2008; Schwanen \& Kwan, 2008). In contrast, much less is known about the impact of ICTs on other forms of spatial mobility such as residential mobility and inter-regional migration.

Several studies argue that ICTs enhance inter-regional migration by (1) improving the quality and quantity of spatial information on distant locales (Dekker \& Engbersen, 2014; Dekker, Engbersen, \& Faber, 2015; Thulin \& Vilhelmson, 2014; Vilhelmson \& Thulin, 2013), (2) permitting migrants to communicate more effectively with people and places left behind (Barcus \& Brunn, 2010; Dekker \& Engbersen, 2014; Komito, 2011), and (3) allowing more freedom to choose a place of residence less on the basis of proximity to a fixed place of work and more on the basis of other geographic characteristics such as natural and cultural amenities (Ettema, 2010; Mokhtarian, Collantes, \& Gertz, 2004; Ory \& Mokhtarian, 2006).

Nonetheless, Cooke (2013) finds a strong negative correlation between the widespread adoption of ICTs over the last 35 years and the steady long-term decline in migration within the United States over the same time period (see Cooke, 2011; Fischer, 2002; Molloy, Smith, \& Wozniak, 2011; Rogerson, 1987; Wolf \& Longino, 2005). He conjectures that in contrast to the idea that ICTs encourage residential change by allowing people to choose where to live independent of a fixed place of work, ICTs may alternatively reinforce residential rootedness because a job change - or similar life course events - may allow people to avoid an unwanted move. For example, a growing number of private-sector management and technology companies allow employees to work from home using ICTs (Mateyka \& Rapino, 2012). As a consequence, workers in these industries may not have to relocate as often for employment as they did in the past.

However, empirical evidence as to the relationship between ICTs and both residential mobility and inter-regional migration is limited. For example, Vilhelmson \& Thulin (2013, p. 214) establish that "most young adults in Sweden have adopted communicative practices that integrate the Internet into their migration decision making processes - from the formation of vague plans and thoughts, to more active plans and actual moves". Likewise, Dekker et al. (2015) focus on how the intent to move influences the use of ICTs in making the migration

\footnotetext{
${ }^{1}$ Acknowledgement: The help provided by the staff of the Northern Ireland Longitudinal Study (NILS) and the NILS Research Support Unit is acknowledged. The NILS is funded by the Health and Social Care Research and Development Division of the Public Health Agency (HSC R\&D Division) and NISRA. The NILS-RSU is funded by the ESRC and the Northern Ireland Government. The authors alone are responsible for the interpretation of the data and any views or opinions presented are solely those of the author and do not necessarily represent those of NISRA/NILS.
} 
decision. While these studies establish that the internet may have changed how migration decisions are made what has not been established is a clear link on the effect of ICTs on residential mobility and inter-regional migration.

Toward that end, the objectives of this analysis are twofold: First, the presumption that ICTs enhance inter-regional migration is critically evaluated and the possibility that ICTs retard residential mobility and migration is considered. Second, following a preliminary study by Cooke \& Shuttleworth (Forthcoming), the effect of ICT use on individual residential change and migration is estimated using a unique source of data (the Northern Ireland Longitudinal Study (NILS)). Beyond being a very large sample ( $28 \%$ of the NI population) the NILS provides both a measure of ICT use prior to the observation of a change in residence and an additional variable which enables the estimation of a model that address concerns regarding unobserved heterogeneity bias. The resulting instrumental variable model provides the first insight into how ICTs may be impacting residential mobility and inter-regional migration.

\section{Background}

The widespread presumption is that ICTs enhance inter-regional migration (see some limited evidence in that regard by Bell, Charles-Edwards, Ueffing, Stillwell, Kupiszewski, \& Kupiszewska (2015)). First, Dekker \& Engbersen (2014), (Dekker et al., 2015), (Thulin \& Vilhelmson, 2014), and (Thulin \& Vilhelmson, 2013) argue that ICTs improve the quality and quantity of spatial information, which reduces both the costs and risks associated with migration (also see some speculation on the same by Kaplan \& Schulhofer-Wohl (2017) and Molloy et al. (2011)):

Information can be personalized on demand and matched to individual preferences in relation to central motives for migration. . . This could reduce the friction of distance and encourage migration, alter migration intensity and distance, and change the ranking of motives and preferences (Vilhelmson \& Thulin, 2013, p. 210).

However, empirical evidence directly linking ICTs to migration through this effect is limited. For example, Vilhelmson \& Thulin (2013, p. 214) conclude that "most young adults in Sweden have adopted communicative practices that integrate the Internet into their migration decision making processes - from the formation of vague plans and thoughts, to more active plans and actual moves", but it should be noted that this conclusion is largely based on the analysis of those who have recently moved or have plans to move (also see Thulin \& Vilhelmson, 2014). It may very well be that stayers have also included the internet in their decision to stay. Similarly, Dekker et al. (2015) find that online media use is positively related to migration intentions. But the direction of causality is of concern: Their analysis establishes the effect of migration intentions on the use of ICTs. However, the key question is the impact of ICTs on residential mobility and inter-regional migration decisions. To answer this question requires the transposition of the dependent and independent variable: How does the use of ICTs affect residential mobility and inter-regional migration decisions? 
Second, ICTs may allow migrants (both internal and international) to communicate more effectively with people and places left behind. This may encourage migration by lowering the perceived cost of migration (Komito, 2011). The evidence is likewise limited but nonetheless supportive of this hypothesis. For example, based on a series of interviews with Brazilian, Ukrainian and Moroccan migrants in the Dutch cities of Amsterdam and Rotterdam, Dekker \& Engbersen (2014, p. 405) conclude that " . . social media strengthen the bonding and bridging capital of migrants, as well as their information position. This may lower the threshold to migrate and it may strengthen a migrant's ability to cope successfully with the adversities of migration". Similarly, Barcus \& Brunn (2010, p. 281) draw on interviews and questionnaires from a sample of eastern Kentucky (US) residents and find that ICTs allow migrants to maintain a connection to their previous place of residence " . . thereby allowing migration and settlement in distant locations with minimal loss of connectedness".

Third, ICTs may support working from home which would allow more freedom to choose a place of residence less on the basis of proximity to a fixed place of work and more on the basis of other geographic characteristics such as amenities (Ettema, 2010; Mokhtarian et al., 2004; Ory \& Mokhtarian, 2006). The conclusion from this small body of research - one using a sample of telecommuting California workers (Ory \& Mokhtarian, 2006), and the other two using a Dutch survey (Ettema, 2010; Muhammad, Ottens, Ettema, \& De Jong, 2007) - is clear: The ability to work remotely from home with the aid of ICTs does not apparently result in higher rates of residential mobility; rather, remote work is more likely a way to ameliorate the negative effects of a long commute.

However, against the widespread presumption of an increasingly mobile society, residential relocation and inter-regional migration has actually been declining in the United States where it has declined by nearly 50\% since the early 1980s (see Cooke, 2011, 2013; Fischer, 2002; Molloy et al., 2011; Rogerson, 1987; Wolf \& Longino, 2005) and there is growing evidence that it is likewise declining in many other advanced countries (see Champion, Cooke, \& Shuttleworth, 2018; Champion \& Shuttleworth, 2016a, 2016b), including Northern Ireland (Campbell \& Shuttleworth, 2017). In that regard there are two strands of research, each emerging from a common concern that the migration decline is linked to demographic processes. The first links the migration decline to cohort effects - similar to those proposed by Easterlin (1980) associated with the crowding out of opportunities in housing and labor markets (Cooke, 2018; Pandit, 1997a, 1997b; Plane, 1992; Plane \& Rogerson, 1991; Rogerson, 1987). The second strand focuses on the role of population rate- and composition-effects and finds - at best - only a small role for these in generating the migration decline (see Cooke, 2011; Fischer, 2002; Molloy et al., 2011; Wolf \& Longino, 2005). In response, speculation regarding the migration decline has turned toward what Fischer $(2002$, p. 193) refers to as ". . deep and pervasive... social forces that have encouraged stability". In regard to this rise in "secular rootedness" (Cooke, 2011), Cooke (2013) responds to an observed strong negative correlation between the widespread adoption of advanced ICTs and the long-term decline in US migration rates by speculating that ICTs may be providing new forms of mobility that substitute for migration. Indeed, using methods similar to those presented here, Cooke \& Shuttleworth (Forthcoming) 
present some evidence suggesting that ICTs may be associated with reduced US inter-state migration.

In the light of these trends and arguments, a critical reconsideration of the various explanations for the widespread presumption that ICTs are associated with elevated levels of residential mobility and inter-regional migration is needed since it is possible that similar processes may also, simultaneously, act to retard geographic mobility. First, while ICTs may act to enhance migration by reducing some of the costs of migration, ICTs may likewise reduce migration by reducing the costs of staying. Specifically, before the advent of contemporary ICTs, the penalty associated with not migrating was quite high; immobility meant a reduced ability to access higher education (see Frenette, 2006), reduced career prospects (see Schaeffer, 1985), and isolation from friends and family who had already migrated (see Sjaastad, 1962). Various forms of ICTs reduce these penalties: Isolation from kith and kin who have migrated can now be mediated through social media (see Benítez, 2012), higher education can now be increasingly accessed online (see Allen \& Seaman, 2013), and employers now increasingly support working from a remote location (see Mateyka \& Rapino, 2012). Indeed, ICTs are central to new forms of spatial mobility that provide alternatives to migration, such as workers who root themselves in a global city with a well-connected low-cost airline hub, allowing them to occasionally commute to remote employment centers while more frequently working from home (see Button \& Vega, 2008; Skeggs, 2004). In essence, migration is no longer as necessary as it once was. Stated differently, in the past the cost to staying was high, but the widespread adoption of ICTs has reduced the penalty - or opportunity costs - of not moving.

Second, an important impact of ICTs on the decision to move is that they reduce the risks associated with migration. That is, ICT-induced improvements in the quality and quantity of information on distant locales may be associated with more efficient migration behavior. Notably, Allen (1979) focuses on the role of information in return and onward migration. He notes that migration entails a certain amount of risk and therefore a certain number of migration decisions will be poor decisions resulting in either return or onward migration. Improvements in the quality and quantity of information on potential migration destinations increase the efficiency of the migration decision itself and, in the process, reduces the possibility of return and onward migration. Similarly, Davanzo (1983) focuses on how the selection of migrants on the basis of unobserved characteristics such as willingness to take on risk is a function of the quality of information:

Since only those who anticipate positive net benefits of migrating will move, initial migration should select against those who underestimate the net returns of migration and attract those who overestimate them. Such selectivity should be stronger the less accurate the information about the potential destination; therefore, the less accurate the information, the more numerous should be the migrants who overestimate the net benefits, encounter disappointment, and become prone to move again (Davanzo, 1983, p. 552). 
Hence, to the degree that ICTs improve the quality and quantity of information about distant locales, ICTs may actually reduce both onward and return migration because they improve the quality of the initial migration decision.

Finally, ICTs not only increase the quality and quantity of information on distant locales but they also simultaneously increase the quality and quantity of information on the current place of residence through the search for jobs, housing, romantic partners, affinity groups, and cultural and political events, and also through the accumulation of much more mundane information such as directions and restaurant reviews. As a consequence, ICTs have been found to increase local civic engagement, a sense of attachment to place, and a sense of community identity (Haythornthwaite \& Kendall, 2010; Kent Jennings \& Zeitner, 2003). In effect, ICTs may actually enhance social capital and community attachment (Mesch \& Talmud, 2010). Indeed, this may explain why the ability to work remotely from home with the aid of ICTs does not apparently result in higher rates of residential mobility; rather, remote work appears to be a tool in avoiding the need to change place of residence in the face of a long commute (Ettema, 2010; Mokhtarian et al., 2004; Ory \& Mokhtarian, 2006). Hence, to the degree that advanced ICTs increase attachment to place, this would also increase the perceived cost of moving and reduce the possibility of moving as a consequence.

Thus, the presumption that advanced ICTs contribute to a more hypermobile society is not necessarily valid with regard to all forms of geographic mobility. That is, while ICTs may be associated with intensified and altered daily mobility behavior they may also, simultaneously, be associated with reduced residential mobility and inter-regional migration. Hence, there is a need to investigate the varying pathways by which ICTs either enhance or retard geographic mobility, the ways in which particular contexts alter the strength of these pathways, and how these result in residential change and inter-regional migration among specific populations. Toward that end, this research focuses on a more fundamental question: Does the use of advanced ICTs have, on average, a net negative or positive effect on residential change and inter-regional migration?

\section{Research Design}

The objective of this paper is to estimate the effect of ICT use on residential change in the form of both residential mobility and inter-regional migration. The dataset for the analysis is drawn from the Northern Ireland Longitudinal Study (NILS) which is unique in that it provides variables reflecting both residential change as well as a measure of ICT use. However, a simple regression estimate of the effect of this measure of ICT use on residential change is likely to be biased due to unobserved heterogeneity (see Angrist \& Pischke, 2009): In this case the unobserved determinants of geographic mobility (e.g., a willingness to take on risk) are probably highly correlated with ICT use. As a consequence, any regression estimate of the effect of ICT use on geographic mobility will reflect not only the direct effect of ICT use but also the indirect effect of any correlated unobserved determinants of relocation. An appropriate resolution to this issue is an instrumental variable (IV) model. Importantly, an IV model requires the identification of an appropriate instrumental variable which is (1) uncorrelated with the unobserved 
determinants of residential mobility and inter-regional migration and (2) is correlated with ICT use (see Angrist \& Pischke, 2009). The NILS database is unique in this regard in that it provides a valid instrument for ICT use (discussed below).

The NILS links a range of administrative and public data to create individual longitudinal histories spanning over 30 years (see Johnston, Rosato, \& Catney, 2010; Shuttleworth \& Martin, 2015). The core of the NILS is a link from the Northern Ireland Health Card Registration (NIHCR) system to the 1981 through 2011 decennial censuses using 104 distinct dates of birth. While the NILS is not a complete count of the population, it does contain a very large sample of individuals representing about $28 \%$ of the 1.8 million people living in Northern Ireland in 2016. Note that (1) the NILS "Distinct Linkage Project" datasets have no identifiable individual level data and are derived from linkages that are anonymized prior to handover to the research team, and (2) access to the NILS is restricted to approved researchers working within a secure data environment.

Importantly, the NILS contains three variables that are key to the estimation of the effect of ICT use on residential mobility and inter-regional migration. First, geographic mobility is measured through reported NIHCR addresses. These changes are then linked to the most recent decennial census in 2011. This structure allows for the measurement of how residential relocations after 2011 are linked to individual, household, and ecological variables as measured in 2011. Second, the NILS also reports whether the 2011 census form was submitted by internet as opposed to other means, such as by mail (Shuttleworth \& Cooke, 2017). The assumption is that individuals who submitted their census form through the internet are more likely to be individuals who intensively use advanced ICTs on a regular basis, since this requires some meaningful knowledge regarding online applications and a familiarity and comfort about using the internet to transmit sensitive personal information to a government agency. Note that this means the sample is thereby limited to the particular householder who actually submitted the census form by mail or internet; where a householder is defined as a resident of a housing unit who at least jointly owns or rents the accommodation and/or is at least jointly responsible for paying the household bills and expenses.

Third, the NILS also includes an appropriate instrument for ICT use: NISRA constructs a "Proximity to Services" variable for each of 5,022 Output Areas, reflecting proximity to a range of services based upon both the local availability and relative proximity to a wide range of public and private services (NISRA, 2010). With respect to the requirements of an instrumental variable model, the first assumption is that Proximity to Services is strongly correlated with whether an individual actually submitted their census form by internet. In this regard it is presumed that areas with poor proximity to services are also likely to be areas with a more poorly developed internet infrastructure.

More importantly, the second presumption is that there is no relationship between the instrumental variable (Proximity to Services) and the unobserved determinants of migration. This presumption cannot be empirically tested because it involves - by definition - an unobservable variable (see Angrist \& Pischke, 2009). Yet it is important to justify. Indeed, 
assuming that Proximity to Services is a proxy for isolation or remoteness, it is plausible that migration self-selection could result in the sorting of residents between more and less remote areas in a manner which is strongly correlated with the unobserved characteristics in question. This may also foster differences in attitudes toward migration between more and less remote locations. However, this is not as great of a concern in Northern Ireland as it would be in a large country like the US or Germany; Northern Ireland is small and compact, nowhere are places less than a 2 hour drive apart, and a well-defined urban hierarchy allows residents of nearly any locale to access urban opportunities through a reasonable commute (Moss, Jack, \& Wallace, 2004). Hence, migration is not as necessary for gaining access to urban opportunities as it may be in larger countries (Stockdale \& Catney, 2014). As a consequence, it is unlikely that there is a strong sorting of unobserved propensities for migration by place of residence in such a way as to be correlated with the instrumental variable.

The analytical sample consists of 294,095 householders between the ages of 16 and 74 who submitted their household's 2011 Census form and who were also part of the NIHCR system in April 2015. Residential change and migration is measured in three ways by comparing place of residence immediately after the March 27, 2011 census to place of residence in April 2015: 1) within-country changes in residence, 2) within-country changes in residence of greater than or equal to $20 \mathrm{~km}$, and 3) within country changes in residence of greater than or equal to $50 \mathrm{~km}$. Table 1 provides some preliminary descriptive statistics which help describe the structure of the data. Most importantly, 26.3\% of the sample changed their place of residence between 2011 and $2015,2.0 \%$ moved greater than $20 \mathrm{~km}$, and only $0.7 \%$ moved greater than $50 \mathrm{~km}$. NI's interregional migration rate is much lower than for most countries, reflecting both its small compact size and the aforementioned accessible urban system. Consistent with generally accepted migration patterns, Table 1 also indicates that younger persons are more likely to change their place of residence and to move long distances. Table 1 also indicates that residential change and migration are positively correlated with internet use. Indeed, rates of residential change and migration are more common among younger populations and internet users. While this data would seem to indicate that internet use contributes to higher migration rates, this conclusion is not warranted. Clearly, residential change and migration, age, and internet use are all highly correlated with each other. To tease out the effects of internet use on residential change and migration it is necessary to address the effects of observed variables, such as age, as well as the aforementioned impacts of unobserved variables on this focal relationship.

Toward that end, the analysis includes a suite of additional independent variables (see Table 2 for variable names, definitions, and means). These include a set of human capital variables related to residential change (see Sjaastad, 1962): Employment Status, Educational Credentials, and Occupation. Another suite of variables are included reflecting the influence of life course characteristics on residential change (see Clark, 1986): Age, Gender, Housing Tenure, Health Status, Household Structure, Household Size, and Previous Moves. Finally, given the importance of religion in shaping residential outcomes in Northern Ireland (Shuttleworth \& Lloyd, 2009), the analysis includes an appropriate set of appropriate variables. 
Finally, the particular functional form of the instrumental variable model of the effect of ICT use on residential relocation in Northern Ireland is shaped by the fact that the outcomes of interest in this particular case - residential change and migration - are a binary categorical variables. In this regard, Angrist \& Pischke (2009) indicate that the appropriate specification is a bivariate probit model with an endogenous treatment effect:

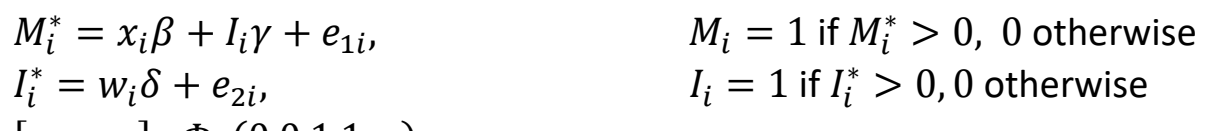

where $\mathrm{M}^{*}$ and $\mathrm{I}^{*}$ are unobserved latent variables, $\rho$ is the correlation between the unobserved determinants of migration $\left(\mathrm{e}_{1 \mathrm{i}}\right)$ and ICT use $\left(\mathrm{e}_{2 \mathrm{i}}\right)$, and $\varphi$ is the standard normal density function. This model is estimated using the biprobit procedure in Stata (Statacorp, 2015).

\section{Results}

The analysis begins by focusing in-depth on the model of residential change and then, because outputs from an IV model are extensive, presents more limited summary results of the two models of migration, one for moves of greater than or equal to $20 \mathrm{~km}$ and the other for moves of greater than or equal to $50 \mathrm{~km}$. The first analysis, of residential change, proceeds sequentially starting with a model with no control variables (Model 1), to a model with the full set of previously discussed control variables (Model 2), and then to the final instrumental variable model (Model 3). Table 3 reports the results of all three models. However, the parameters of the probit models as reported in Table 3 have little direct intuitive meaning beyond sign and significance. This is of particular importance in identifying the estimated effect of ICT use on residential change. Therefore, the effects of the internet variable on migration are reported in terms of average marginal effects in Table 4 (see Williams (2012)). These provide an estimate of the effect of ICT use on the probability of changing residence while holding all other variables at their observed values. Hence, for Model 1 (a naïve model with no covariates) the average marginal effect of internet use is $2.7 \%$ and is statistically significant (see Table 4); that is, individuals who submitted their census form by internet are $2.7 \%$ more like to change their place of residence between 2011 and 2015. Note, however that this is merely the average difference in the probability of residential change without adjusting for either observed or unobserved heterogeneity and, as such, mirrors the results presented in Table 1. As a consequence, no meaningful inference should be attributed to it.

At a minimum, it is necessary to addressed the effects of observed heterogeneity by including relevant control variables. Toward that end, Model 2 (see Table 3 ) reports the results of a probit model of the probability of residential change as a function of internet use along with the full set of control variables. Setting aside for the moment the role of the internet in shaping residential mobility, the parameter estimates for the control variables conform to general expectations. With regard to the human capital variables, residential mobility is generally higher for those working full-time relative to all other employment statuses, lower for those with a vocational degree relative to all other employment statuses, and highest for those in 
managerial occupations. The effect of the life course variables on residential mobility also conform to general expectations: Residential mobility decreases with age, homeownership, poor health (Darlington, Norman, \& Gould, 2015), and household complexity, while it is higher for women, and those who have previously moved. The effects of religion are consistent with previous research on higher rates of mobility among Protestants relative to Catholics (Shuttleworth, Barr, \& Gould, 2013).

Most significantly, Model 2 also indicates that, after controlling for sources of observed heterogeneity, the estimated effect of internet use is not statistically different from zero. A more generous interpretation is that the parameter estimate is negative and could be generously considered to be marginally significant at a $p$-value of 0.068 . This translates into a marginal effect of internet use on residential change of $-0.4 \%$ (see Table 4 ). While hardly a large parameter estimate this is a meaningful finding unto itself. Not only does this contradict the presumption that ICTs contribute to greater residential mobility, but it contradicts the general narrative that the widespread adoption of ICTs is contributing to the emergence of a hypermobile society.

However, in this case it is not only necessary to control for sources of observed heterogeneity, but it is also necessary to control for sources of unobserved heterogeneity. Toward that end, IV estimates are reported in Table 3 (see Model 3). In this case, the method requires the estimation of two models. The first is a model of the probability that a sample member submitted their Census form by internet and the second is the focal model of residential change which includes the instrument for whether an individual submitted the Census form by internet. With regard to the first model of internet use, the instrumental variable methodology requires that all of the variables included in the focal model of residential change are included as independent variables regardless of whether they have any theoretical link to the IV. In this regard, the parameter estimates for submitting the Census form have little relevant meaning. The only important component of the first model is the relationship between the instrument Proximity to Services - and internet submission of the Census form. In this case, this indicates that there is significant negative relationship suggesting that independent of all other variables that people who live in more geographically isolated areas are less likely to submit their Census form by internet.

Once more setting aside for the moment the role of the internet in shaping residential mobility, Table 2 provides the parameter estimates for the same set of independent variables as reported for Model 2. In this regard, there are few meaningful changes in the relationships described for Model 1. Indeed, to a certain degree, there are a greater number of statistically significant parameters. Most importantly, Model 3 also indicates that, after controlling for sources of both observed and unobserved heterogeneity, the estimated effect of internet use is both negative and statistically significant, indicating that individuals who submitted their 2011 Census form through the internet were less likely to have changed their place of residence between 2011 and 2015. Specifically, Table 4 indicates that the marginal effect of using the internet to submit the Census form is $-10.3 \%$, independent of both observed and unobserved effects. Stated differently, using the internet to submit the 2011 Census form is associated with 
an $10 \%$ reduction in residential mobility between 2011 and 2015 relative to those who submitted the Census form by mail.

Finally, Table 4 also provides the estimated marginal effects of ICT use on migration greater than or equal to $20 \mathrm{~km}$ and greater than or equal to $50 \mathrm{~km}$. Full model results are not presented but closely conform to the estimates for the model of all residential changes provided in Table 2. These estimates indicate that ICT use is associated with a $6.6 \%$ decline in migration greater than or equal to $20 \mathrm{~km}$ and a $1.6 \%$ decline in migration great than or equal to $50 \mathrm{~km}$. Hence, it appears that while ICT use is associated with lower rates of residential mobility and migration that the effect is focused on short-distance moves. This is particularly interesting give that Table 1 shows that internet users tend to be younger and that younger populations are more likely to move long distances.

Two caveats regarding these estimates of the effect of submitting the Census form by internet are in order. First, while IV models are designed to determine causality, it is not reasonable to argue that the actual act of submitting the Census form by internet causes an immediate decline in the probability of changing residence and migrating. Rather, it is important to remember that Census submission through the internet is selected as a proxy for the degree to which an individual is both familiar and comfortable enough with ICT technologies to transmit private information to a government agency through the internet. Hence, the correct interpretation is that people who use ICTs intensively are also much less likely to change their place of residence, independent of both observed and unobserved sources of heterogeneity. Second, the estimated effect of internet submission on residential change is very large $(-10.3 \%)$. Note, however, that this result is complement by, first, the results of Model 2 which indicate that when only observed variables are included in the model that there is only a small - and marginally significant - negative effect of internet submission and by, second, the results for the models of migration which also suggests that this effect is small in these cases. Altogether, these results indicate - at the least - that ICT use does not enhance all forms of geographic mobility. Indeed, it appears that ICT use may actually reduce residential change and migration.

\section{Conclusions}

The dominant narrative is that the widespread adoption of ICTs contributes to the emergence of a more geographically mobile society and, more specifically, ICTs enhance residential change and both inter-regional and international migration. However, this research demonstrates that ICTs may actually be associated with reduced levels of residential mobility and inter-regional migration. These results add complexity and nuance to the narrative of both the emergence of a more mobile society and the role of ICTs in these transformations. Importantly, these are not necessarily contradictory behaviors. One of the hypotheses for the negative effect of ICTs on residential mobility is that ICTs provide a means to avoid the disruption of residential mobility but, at the same time to allow people to access new employment opportunities, higher education, and maintain inter-personal relationships from a distance while remaining rooted in a more permanent residential space. In a sense, this is akin to global circulation: Just as some families maintain residences in two distinct locales and circulate between those residences on 
an irregular basis in order to minimize economic risk, ICTs may allow people to maintain their current residential location while simultaneously gaining access to a wider range of opportunities - both through actual shorter term geographical movement or through the internet - to minimize risk. This last point may be of particular significant impact at the moment due to rising levels of economic insecurity (see Morrison \& Clark (2016) for some interesting comments on migration and economic insecurity).

This interpretation is countered by another: The analysis finds that the effects of ICT use on residential change and migration is greatest for short-distance moves. Hence, this indicates that more attention needs to be paid to how ICTs may root people to their current locales rather than providing alternatives to migration. Future research should more fully consider the role of the previously discussed possibility that ICTs may increase the quality and quantity of information on the current local and thereby increase attachment to place; all of which would increase the perceived cost of even relatively short moves. Another avenue for investigation is that ICTs may be the medium through which desires to remain rooted in an increasingly insecure economic environment are made possible.

Finally, this research has merely established the direction of causality and has not clearly identified the pathways for that relationship: Does the use of advanced ICTs have, on average, a net negative or positive effect on geographic mobility? However, there is a need to investigate the varying pathways by which ICTs either enhance or retard geographic mobility. Several alternative hypotheses have been outlined which include possible ways in which ICTs provide alternatives to migration, how ICT-enhanced improvements in the flow of information might reduce return migration, and the role of ICTs in enhancing attachment to place. The difficulty in directly testing these hypotheses is the dearth of individual-level data regarding geographic mobility and ICT use (along with any necessary instruments). As a consequence, the likely means for investigating these hypothesis is either through comparative geographic research which would take advantage of the ways in which particular contexts alter the strength of these pathways, along with more qualitative approaches to understanding how advanced ICTs shape and mold residential decision-making.

\section{REFERENCES}

Allen, I. E., \& Seaman, J. (2013). Changing course: Ten years of tracking online education in the United States. Babson Park, MA: Babson Survey Research Group.

Allen, J. (1979). Information and subsequent migration: Further analysis and additional evidence. Southern Economic Journal, 45(4), 1274-1284.

Angrist, J. D., \& Pischke, J. (2009). Mostly harmless econometrics. Princeton, NJ: Princeton University Press.

Barcus, H. R., \& Brunn, S. D. (2010). Place elasticity: Exploring a new conceptualization of mobilty and place attachment in rural America. Geografiska Annaler: Series B, Human Geography, 92(4), 281-295. 
Bell, M., Charles-Edwards, E., Ueffing, P., Stillwell, J., Kupiszewski, M., \& Kupiszewska, D. (2015). Internal migration and development: Comparing migration intensities around the world. Population and Development Review, 41(1), 33-58.

Benítez, J. L. (2012). Salvadoran transnational families: ICT and communication practices in the network society. Journal of Ethnic and Migration Studies, 38(9), 1439-1449.

Button, K., \& Vega, H. (2008). The effects of air transportation on the movement of labor. GeoJournal, 71(1), 67-81.

Campbell, B., \& Shuttleworth, I. (2017). Understanding declining address changing rates in Northern Ireland, 1981-2011: A decomposition approach. Paper presented at the RGSIBG Annual International Conference, London, UK.

Champion, T., Cooke, T. J., \& Shuttleworth, I. (Eds.). (2018). Internal migration in the developed world: Are we becoming less mobile? Routledge: London, UK.

Champion, T., \& Shuttleworth, I. (2016a). Are people changing address less? An analysis of migration within England and Wales, 1971-2011, by distance of move. Population, Space and Place.

Champion, T., \& Shuttleworth, I. (2016b). Is longer-distance migration slowing? An analysis of the annual record for England and Wales since the 1970s. Population, Space and Place.

Clark, W. A. V. (1986). Human migration. Beverly Hills, California: Sage.

Cooke, T. J. (2011). It is not just the economy: Declining migration and the rise of secular rootedness. Population, Space and Place, 17(3), 193-203.

Cooke, T. J. (2013). Internal migration in decline. The Professional Geographer, 65(4), 664-675.

Cooke, T. J. (2018). United States: Cohort effects on the long-term decline in migration rates. In Champion, T., Cooke, T. J., \& Shuttleworth, I. (Eds.) Internal migration in the developed world: Are we becoming less mobile? (pp. 101-119). Routledge: London.

Cooke, T. J., \& Shuttleworth, I. (Forthcoming). Migration and the internet. Migration Letters.

Darlington, F., Norman, P., \& Gould, M. (2015). Health and internal migration.

DaVanzo, J. (1983). Repeat migration in the United States: Who moves back and who moves on? The Review of Economics and Statistics, 65(4), 552-559.

Dekker, R., \& Engbersen, G. (2014). How social media transform migrant networks and facilitate migration. Global Networks, 14(4), 401-418.

Dekker, R., Engbersen, G., \& Faber, M. (2015). The use of online media in migration networks. Population, Space and Place, 22(6), 446-462.

Easterlin, R. A. (1980). Birth and fortune: The impact of numbers on personal welfare. New York, NY: Basic Books.

Ettema, D. (2010). The impact of telecommuting on residential relocation and residential preferences, a latent class modeling approach. Journal of Transport and Land Use, 2010(3), 7-24.

Fischer, C. S. (2002). Ever-more rooted Americans. City \& Community, 1(2), 177-198.

Frenette, M. (2006). Too far to go on? Distance to school and university participation. Education Economics, 14(1), 31-58.

Haythornthwaite, C., \& Kendall, L. (2010). Internet and community. American Behavioral Scientist, 53(8), 1083-1094.

Johnston, F., Rosato, M., \& Catney, G. (2010). The Northern Ireland longitudinal study: An introduction NILS. Retrieved from Belfast, UK: 
Kaplan, G., \& Schulhofer-Wohl, S. (2017). Understanding the long-run decline in interstate migration. International Economic Review, 58(1), 57-94.

Kent Jennings, M., \& Zeitner, V. (2003). Internet use and civic engagement: A longitudinal analysis. Public Opinion Quarterly, 67(3), 311-334.

Komito, L. (2011). Social media and migration: Virtual community 2.0. Journal of the American society for information science and technology, 62(6), 1075-1086.

Mateyka, P., \& Rapino, M. (2012). Home-based workers in the United States: 2010. Washington, DC: United States Census Bureau.

Mesch, G. S., \& Talmud, I. (2010). Internet connectivity, community participation, and place attachment: A longitudinal study. American Behavioral Scientist, 53(8), 1095-1110.

Mokhtarian, P. L., Collantes, G. O., \& Gertz, C. (2004). Telecommuting, residential location, and commute-distance traveled: Evidence from state of California employees. Environment and Planning A, 36(10), 1877-1897.

Molloy, R., Smith, C. L., \& Wozniak, A. (2011). Internal migration in the United States. Journal of Economic Perspectives, 25(2), 1-42.

Morrison, P. S., \& Clark, W. A. (2016). Loss aversion and duration of residence. Demographic Research, 35, 1079.

Moss, J. E., Jack, C. G., \& Wallace, M. T. (2004). Employment location and associated commuting patterns for individuals in disadvantaged rural areas in Northern Ireland. Regional Studies, 38(2), 121-136.

Muhammad, S., Ottens, H. F., Ettema, D., \& de Jong, T. (2007). Telecommuting and residential locational preferences: A case study of the Netherlands. Journal of Housing and the Built Environment, 22(4), 339-358.

NISRA. (2010). Northern Ireland multiple deprivation measure 2010: Description of indicators, domains and the multiple deprivation measure. Belfast, NI.

Ory, D. T., \& Mokhtarian, P. L. (2006). Which came first, the telecommuting or the residential relocation? An empirical analysis of causality. Urban Geography, 27(7), 590-609.

Pandit, K. (1997a). Cohort and period effects in US migration: How demographic and economic cycles influence the migration schedule. Annals of the Association of American Geographers, 87(3), 439-450.

Pandit, K. (1997b). Demographic cycle effects on migration timing and the delayed mobility phenomenon. Geographical Analysis, 29(3), 187-199.

Plane, D. A. (1992). Age-composition change and the geographical dynamics of interregional migration in the U.S. Annals of the Association of American Geographers, 82(1), 64-85.

Plane, D. A., \& Rogerson, P. A. (1991). Tracking the baby boom, the baby bust, and the echo generatios: How age composition regulates US migration. Professional Geographer, 43(4), 416-430.

Rogerson, P. A. (1987). Changes in U.S. National mobility levels. The Professional Geographer, 39(3), 344-351.

Schaeffer, P. V. (1985). Human capital accumulation and job mobility. Journal of Regional Science, 25(1), 103-114.

Schwanen, T., Dijst, M., \& Kwan, M.-P. (2008). Icts and the decoupling of everyday activities, space and time: Introduction. Tijdschrift voor economische en sociale geografie, 99(5), 519-527. 
Schwanen, T., \& Kwan, M. (2008). The internet, mobile phone and space-time constraints. Geoforum, 39, 1362-1377.

Shuttleworth, I., Barr, P. J., \& Gould, M. (2013). Does internal migration in Northern Ireland increase religious and social segregation? Perspectives from the Northern Ireland longitudinal study (NILS) 2001-2007. Population, Space and Place, 19(1), 72-86.

Shuttleworth, I., \& Cooke, T. J. (2017). Internet response in the UK 2011 census: The example of Northern Ireland. School of Natural and Built Environment, Queen's University Belfast.

Shuttleworth, I., \& Martin, D. (2015). People and places: Understanding geographical accuracy in administrative data from the census and healthcare systems. Environment and Planning A, $0308518 \times 15618205$.

Shuttleworth, I. G., \& Lloyd, C. D. (2009). Are Northern Ireland's communities dividing? Evidence from geographically consistent census of population data, 1971-2001. Environment and Planning A, 41(1), 213-229.

Sjaastad, L. A. (1962). The costs and returns of human migration. The Journal of Political Economy, 70(5), 80-93.

Skeggs, B. (2004). Class, self, culture. Transformations: Thinking through feminism: London: Routledge.

StataCorp. (2015). Stata statistical software: Release 14. College Station, TX: StataCorp LP.

Stockdale, A., \& Catney, G. (2014). A life course perspective on urban-rural migration: The importance of the local context. Population, Space and Place, 20(1), 83-98.

Thulin, E., \& Vilhelmson, B. (2013). Virtual practices and migration plans: A qualitative study of urban young adults. Population, Space and Place.

Thulin, E., \& Vilhelmson, B. (2014). Virtual practices and migration plans: A qualitative study of urban young adults. Population, Space and Place, 20(5), 389-401.

Vilhelmson, B., \& Thulin, E. (2013). Does the internet encourage people to move? Investigating Swedish young adults' internal migration experiences and plans. Geoforum, 47, 209-216.

Williams, R. (2012). Using the margins command to estimate and interpret adjusted predictions and marginal effects. Stata Journal, 12(2), 308-331.

Wolf, D., \& Longino, C. (2005). Our 'increasingly mobile society?' The curious persistence of a false belief. The Gerontologist, 45, 5-11. 


\section{Acknowledgement}

The help provided by the staff of the Northern Ireland Longitudinal Study (NILS) and the NILS Research Support Unit is acknowledged. The NILS is funded by the Health and Social Care Research and Development Division of the Public Health Agency (HSC R\&D Division) and NISRA. The NILS-RSU is funded by the ESRC and the Northern Ireland Government. The authors alone are responsible for the interpretation of the data and any views or opinions presented are solely those of the author and do not necessarily represent those of NISRA/NILS.' 